\title{
Investigating the Future of Self-Service Technology
}

\author{
Paul Robertson \\ University of Abertay Dundee \\ Dundee, DD1 HG \\ p.robertson@abertay.ac.uk
}

\author{
Andrea Szymkowiak \\ University of Abertay Dundee \\ Dundee, DD1 HG \\ shtas@abertay.ac.uk
}

\author{
Graham Johnson \\ NCR Discovery Centre \\ 3 Fulton Road, Dundee, DD2 4SW \\ graham.johnson@ncr.com
}

\begin{abstract}
In this paper we describe an ongoing research project between NCR Dundee and Abertay University to investigate the future of self-service technology for entertainment. The aim was to assess how future technologies may be utilized in building a new system or improving current approaches to content distribution. We designed a web-based survey to determine the likelihood with which users would interact with future services. The findings suggested a strong preference for internet based technologies and the implications for further usage technologies are discussed.
\end{abstract}

\section{Self-service technology, Web-survey}

\section{INTRODUCTION}

The proliferation of new technologies allows for various ways to access a multitude of entertainment materials, such as games, music, audio books or films. Access to materials itself can be, and is, provided in endless ways from walking to shops to rent or purchase films or music DVDs, using DVD postal rental services (e.g. LoveFilm, WHSmiths), purchasing/renting material via the Internet (e.g. Amazon), to downloading mobile phone applications for smart phones, and in-home providers (e.g. Virgin Media, Sky's SkyPlayer, BBC's iPlayer and Apple TV) to name but a few services in the UK. Internetbased access can be seen as a form of self-service on the part of the users, as they are in charge of the time and place of the transaction. In addition, a new development in recent years is the installation of specifically designed self-service technologies in malls or supermarkets as an ever increasing form of accessing entertainment technologies. A number of manufacturers (e.g. NCR, Red box) have developed kiosk-based systems to distribute films and these systems are already in use in Japan [1] and the US [2]. Interaction with these systems usually consists of the user selecting a film or game using a touch screen, paying for the product via a card reader, and the kiosk distributes a DVD containing the selected media. Once the user wants to return the DVD they revisit a kiosk for drop-off. All of these systems have to address a number of concerns relating to the access, use and return and/or automated cancellation of access to the media. These include copyright issues, convenience of access, quality of the product, transaction security and service and product acceptance on the part of the user. The last issue may arise as a result of the interaction with the technology service and user satisfaction with the selected product with respect to its function [9], or user attitudes [7]. Consumer studies show that consumer demographics such as age and gender are associated with particular usage patterns and expectations when engaging in shopping transactions in both physical and virtual stores. Burke [8] showed that young age groups $(a g e<25)$ are more interested in using newer technologies, including phones and interactive kiosks, than older age groups. In addition, males more strongly prefer the use of technology, including the Internet, compared with females [8].

For self-service technologies in particular, researchers have shown that user characteristics like personality traits [12] and perceived personal control [10] can influence the acceptance of these systems, in addition to the system's perceived usefulness and superiority over other systems [11]. Thus, a number of user attitudes and perceptions are crucial to the uptake of such systems, and need to be gauged in the design of technologies.

This project focused on the assessment of likelihood of usage patterns of future entertainment technologies in the UK. We defined a 'future' technology as a technology that was: not available in the UK; a technology with only partial implementation of key components; or a technology that awaits further distribution in the market. Based on the reviewed literature we hypothesized that we would find a difference in age groups regarding the likelihood of technology uptake. It should be noted that familiarity and usage likelihood could be confounded with age in that older adults may be less familiar with technologies due to the digital divide. Thus, we also tested whether experience with digital technologies, measured by a technical competence score would influence the usage of newer technologies, irrespective of gender or age. In addition, we also 
expected gender differences in the uptake, with males showing a more favorable attitude to future technologies, based on the study by Burke [8].

\section{METHODOLOGY}

\subsubsection{Participants}

Our survey comprised 182 complete responses, providing an age range for respondents from 18 to 60 years of age with a mean age of 25 . Furthermore, there was an even split for gender with 90 males and 90 females, with 2 respondents opting not to state gender.

\subsubsection{Intranet Survey}

The online survey was approved by the University's School of Social and Health Sciences Ethics Committee. The survey sections focused on content distribution methods, such as buying/renting in store, online and through the TV, and the likelihood that participants would use the proposed future systems (see below). As the survey was comprehensive, we limit reporting here to selected areas of interest with respect to addressing our predictions above.

Technical competency was addressed by asking participants to indicate with which computer tasks they engaged with from a prescribed list. This list comprised the following options: office/business related tasks, gaming, internet and email, social networking, photo and/or video editing, education, development/programming, playing music, watching videos, other. Thus, participants were attributed a score between 0 and 10 , where 10 represented the highest technical competency score, reflecting engagement with all computer tasks, and 0 represented the lowest score, representing no task engagement.

Participants were given descriptions of future technical technologies that comprised the following information (N.B. the actual descriptions were more specific than presented here as they were linked in with a wider set of questions (not shown) and other contextual information; however, the descriptions given below, supported by references where appropriate, of the different system types are sufficient to interpret the analyses):

DVD Kiosks work in a similar manner to food vending machines, but instead of buying confectionary users can rent DVDs. DVD Kiosks are widely available in the USA but until recently have not been available within the UK [4].

Digital Download Kiosks allow users to rent content by transferring a digital copy to a memory stick, which can then be viewed through a TV or custom media player. Digital download kiosks entered a trial period in late 2009 in the UK and US [2].

Internet Streaming of content would allow users to access content through a wide range of devices (from TVs to mobile phones) via the Internet. The concept is similar to that of the BBC iPlayer but would provide a greater amount of content [3].

Finally, Internet Downloading of content would provide legal transfer of content from the Internet to a local device. This approach enables users to view content they have already downloaded without requiring an active Internet connection.

\subsubsection{Procedure}

Upon logging in to the web-based survey form, participants input their demographic data on age and gender, and also technical competency. The future technology scenarios were described in the survey so participants could form an idea about the envisaged technology and how it may be used. Their responses were collected using a 5 point Likert scale, with the likelihood of usage being categorized as: 1 - very likely; 2 - likely; 3 - neither; 4 - unlikely; and 5 - very unlikely. The survey ran online for 2 months via Abertay University's Intranet, and this allowed both University students and members of staff to participate. To provide an incentive for participation, completion of the survey allowed participants to enter into a prize draw, where two Amazon vouchers for $£ 100$ could be won.

Findings

Technical competence was measured based on the number of computer tasks participants engaged with. As Table 1 shows, most participants engage with approximately 7 of the listed computer tasks and few respondents were scored at either extreme of our scale (i.e. at 10 or below 2), and this indicated a fair level of technical competence across the respondents. Table 2 depicts the type of tasks the users' engaged with. The most common computer task was Internet and email; with almost every respondent selecting that task $(95.6 \%)$, followed by watching videos (83\%) and social networking (82.4).

Table 1. Number of tasks participants performed using a computer

\begin{tabular}{|c|c|c|}
\hline $\begin{array}{c}\text { Number of } \\
\text { tasks }\end{array}$ & $\begin{array}{c}\text { Number of } \\
\text { participants }\end{array}$ & $\%$ \\
\hline 0 & 2 & 1.1 \\
\hline 1 & 3 & 1.6 \\
\hline 2 & 3 & 1.6 \\
\hline 3 & 6 & 3.3 \\
\hline 4 & 11 & 6 \\
\hline 5 & 26 & 14.3 \\
\hline 6 & 38 & 20.9 \\
\hline 7 & 50 & 27.5 \\
\hline 8 & 18 & 9.9 \\
\hline 9 & 20 & 11 \\
\hline 10 & 5 & 2.8 \\
\hline
\end{tabular}


Table 2. Percentage of users who engaged with a task

\begin{tabular}{|c|c|}
\hline Task & $\begin{array}{c}\text { Percentage of } \\
\text { Participants }\end{array}$ \\
\hline Office/Business related tasks & $45.1 \%$ \\
\hline Gaming & $57.7 \%$ \\
\hline Internet and email & $95.6 \%$ \\
\hline Social networking & $82.4 \%$ \\
\hline Photo and/or video editing & $62.6 \%$ \\
\hline Education & $81.9 \%$ \\
\hline Development/Programming & $35.2 \%$ \\
\hline Play music & $82.4 \%$ \\
\hline Watching videos & $83 \%$ \\
\hline Other & $7.7 \%$ \\
\hline
\end{tabular}

In the following sections we report on the effects of gender, age, and technical competence.

A comparison of the respondents' likelihood to use each of the 4 proposed future technology systems was performed using a non-parametric KruskallWallis test on gender as a grouping variable and ratings ranging from 1-5 for each system. P-values are listed for each future technology in Table 3 . The results showed a significant difference for gender for the Internet streaming system only. All participants were likely to use this technology, but females were less likely than males to use this system (mean rating for males $=1.47$, and females $=1.83$ ). There were no significant gender differences for all other technologies, all $p$ values $>0.05$.

To assess the effect of age, a Spearman correlation between age and likely usage ratings (1-5) was calculated for each of the technologies separately. There were no significant correlations for the technologies (see Table 3 for $p$-values). There was a slight but non-significant trend for unlikely use of technology with increasing age for all four systems, but especially for Internet streaming.

Finally, to assess the effect of technical competence, a Spearman correlation was conducted for the likelihood of usage (1-5) and the technical competency score (0-10) for each system. For both, DVD Kiosk and Digital Download Kiosk no significant association could be found. However, the correlations were significant for Internet Streaming and Internet Download. (see Table 3 for p-values). Participants were more likely to use both systems with increasing technical competence.
Table 3. p-values for Gender, Age and Technical competence in relation to future technology usage

\begin{tabular}{|c|c|c|c|}
\hline Technologies & Gender & Age & $\begin{array}{c}\text { Technical } \\
\text { competence }\end{array}$ \\
\hline DVD Kiosk & $\begin{array}{c}\mathrm{p}=0.141 \\
\mathrm{X} 2=2.164\end{array}$ & $\mathrm{p}=0.811$ & $\mathrm{p}=0.468$ \\
\hline $\begin{array}{c}\text { Digital Download } \\
\text { Kiosk }\end{array}$ & $\begin{array}{c}\mathrm{p}=0.932 \\
\mathrm{X} 2=0.007\end{array}$ & $\mathrm{p}=0.456$ & $\mathrm{p}=0.922$ \\
\hline $\begin{array}{c}\text { Internet } \\
\text { Streaming }\end{array}$ & $\begin{array}{c}\mathrm{p}=0.036 \\
\mathrm{X} 2=4.378\end{array}$ & $\mathrm{p}=0.100$ & $\mathrm{p}<0.0001$ \\
\hline & & & \\
\hline $\begin{array}{c}\text { Internet } \\
\text { Download }\end{array}$ & $\begin{array}{c}\mathrm{p}=0.151 \\
\mathrm{X} 2=2.064\end{array}$ & $\mathrm{p}=0.491$ & $\mathrm{p}<=0.001$ \\
\hline
\end{tabular}

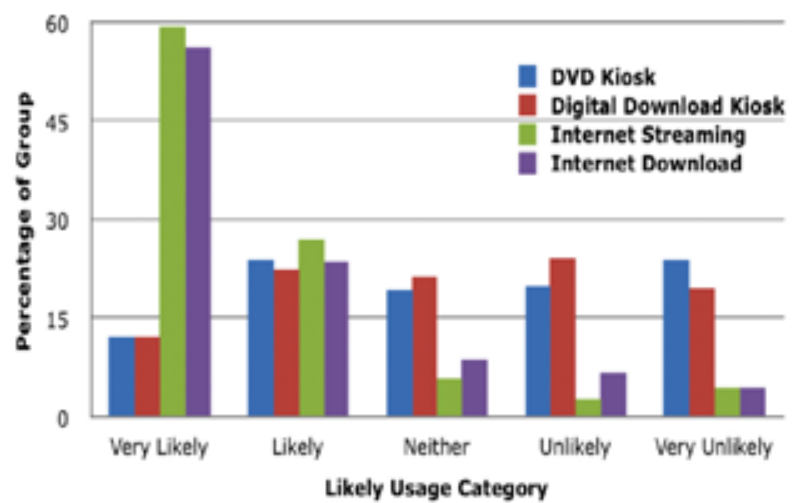

Figure 1. Comparison of likely usage for the possible future systems

Figure 1 depicts likely usage data for each future technology system, averaged over age and gender. However, the only noticeable trend is for Internet Streaming and Internet Download appearing to be more likely to be used overall. The data are more uniform for both Kiosk-based systems.

\section{SUMMARY AND CONCLUSIONS}

The results showed no preference for a particular technology based on Age, which does not support our prediction. One explanation could be that the selected age groups (all University students or staff) were familiar with the use of technology, or that the described technology was not sufficiently distinct. This last argument is inconsistent with a significant effect of technical competency, in that higher technical competency resulted in higher likelihood of usage for both Internet technologies only. Thus, technical competence allowed moderation for perhaps familiar seeming internet technologies.

There was a Gender effect, in that males are more likely than females to engage with Internet Streaming. This would be consistent with our hypothesis, that males are more inclined to engage with new, sophisticated technology which is reflected in other research [8]. Internet downloading - compared 
to internet streaming - is quite common in various other contexts in contrast to internet streaming. We speculate that females were perhaps more familiar with standard internet download use and less familiar with internet streaming which resulted in less usage ratings for this system.

Finally, Technical Competence was only important for both Internet Download and Internet Streaming systems. In light of the recent government agenda to create wider broad band coverage, this is perhaps not surprising as users are likely to have been more exposed to Internet-related activities, and therefore are more familiar with these than with Kiosk-related activities. As part of the Universal Connectivity Commitment the government has pledged a minimum $2 \mathrm{Mbps}$ broadband access to every home in the UK by 2012 [5]. More recent studies [6] showed that the number of homes in the UK with broadband access increased. $99 \%$ of all UK homes and business now have access to ADSL broadband services, with a small number of exchanges not being upgraded to provide ADSL broadband. BT recently announced that it now believes it can provide 2.5 million homes with Fibre-to-the-Premises (FTTP) broadband by 2012. Homes eligible for the FTTP technology will receive broadband speeds up to $100 \mathrm{Mbps}$. Thus, the predominance of Internet based systems can be anticipated, as there is already a functioning infrastructure that is widened even further. Kiosk-based systems have not been extensively implemented in the UK. However, the data indicate that users do not seem to have a strong preference for or against the usage of such systems. Data on their use in the Southern parts of the UK, where they are currently being trialed, will shed more light on their likelihood of uptake and usage patterns and will require comparative analysis in due course. We are also currently conducting the same survey in other nations and cultures to assess potentially different perspectives with respect to technology use.

\section{ACKNOWLEDGMENTS}

This research project was funded by NCR Dundee. We also wish to express our gratitude to the participants who gave their time to complete the web-based survey.

\section{REFERENCES}

[1]

http://www.ncr.com/about_ncr/ media_information/news_releases/2009/ november/110909a.jsp

[2] http://www.ncr.com/about_ncr/ media_information/news_releases/2009/ november/110909a.jsp

[3] http://iplayerhelp.external.bbc.co.uk/help/about_ iplayer
[4] http://www.independent.co.uk/arts-entertainment/ films/news/dvd-rental-machines-to-be-launched-inuk-supermarkets-1782926.html

[5] http://news.bbc.co.uk/1/hi/technology/8298382. stm

[6] http://www.uswitch.com/broadband/ukbroadband/

[7] Aziz, M., Liu, Z., Johnson, G. I., Zhang, H., Chen, J., Wu, H. and Jiang, H. 2007. Investigating the use and adoption of self-service technology in China. In: Universal Access in Human Computer Interaction: Coping with Diversity, 19-27. Lecture Notes in Computer Science (LNCS), (Ed: Constantine Stephanidis). Springer. DOI $=$ http://dx.doi. org/10.1007/978-3-540-73279-2_3.

[8] Burke, R. R. 2002. Technology and the customer interface: what consumers want in the physical and virtual store. Journal of the Academy of Marketing Science 30 (October), 411-432. DOI = 10.1177/009207002236914.

[9] Johnson, G. I. and Westwater, M. G. 1996. Usability and self-service information technology: Cognitive Engineering in Product Design and Evaluation. AT\&T Technical Journal (Special Issue: Information Technology - Design and Development) January/February: 64-73.

[10] Lee, J. and Allaway, A., 2002 Effects of personal control on adoption of self-service technology innovations. Journal of Services Marketing. $16553-$ 572. $\mathrm{DOI}=: 10.1108 / 08876040210443418$.

[11] Meuter, M. L,. Ostrom, A. L., Roundtree, R. I. and Bitner, M.J. 2000. Self-service technologies: understanding customer satisfaction with technology-based service encounters. Journal of Marketing 64 (July 2000), 50-64. DOI $=10.1509 /$ jmkg.64.3.50.18024.

[12] Meuter M. L,. Ostrom, A. L., Bitner, M.J. and Roundtree, R. 2003. The influence of technology anxiety on consumer use and experiences. Journal of Business Research 56, 899-906. DOI = 10.1016/ S0148-2963(01)00276-4. 